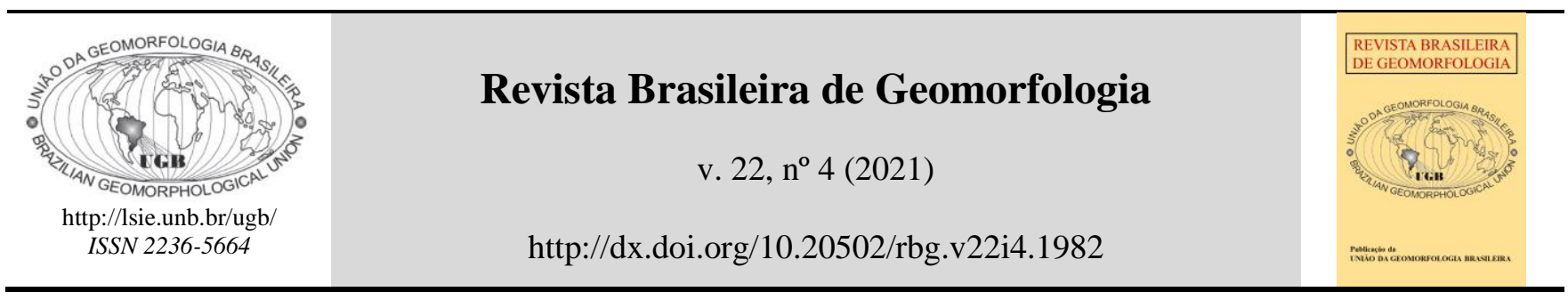

Artigo de Pesquisa

\title{
Mineração de dados na análise dos condicionantes dos movimentos de massa na região serrana do Rio de Janeiro
}

\section{Data mining for analysis of the landslides conditioning factors in the Rio de Janeiro mountainous region}

\section{Louis Felippe Gonçalves de Souza ${ }^{1}$ e Cristiane Nunes Francisco ${ }^{2}$}

1 Universidade Federal Fluminense, Departamento de Geografia, Niterói, Brasil. felippetj@gmail.com. ORCID: https://orcid.org/0000-0003-0903-7101

2 Universidade Federal Fluminense, Departamento de Análise Geoambiental, Niterói, Brasil. cristianenf@id.uff.br. ORCID: https://orcid.org/0000-0002-8688-9810

Recebido: 07/07/2020; Aceito: 20/03/2021; Publicado: 01/10/2021

Resumo: Os movimentos de massa são processos de evolução das encostas que têm como principais condicionantes os elementos físicos. No entanto, estudos sobre a análise espacial da fisiografia conjuntamente com as ocorrências requerem grande volume de dados. Neste sentido, técnicas automatizadas para descoberta de conhecimento podem auxiliar na realização destes estudos. Logo, o objetivo deste trabalho é a aplicação da mineração de dados na descoberta de conhecimento sobre os condicionantes fisiográficos dos movimentos de massa. A área de estudo é a região serrana fluminense onde ocorreu um dos maiores desastres naturais do Brasil em 2011. Foi aplicado o algoritmo Apriori que possibilitou a extração de regras de associação entre as 2,2 mil cicatrizes de movimentos de massa de 2011 e os condicionantes fisiográficos, constituídos pelo uso e cobertura da terra e as variáveis geomorfométricas. As regras revelaram que as cicatrizes prevaleciam em encostas convergentes e côncavas de relevo montanhoso, na faixa altimétrica entre 1.000 e 1.200 m, e cobertas por vegetação herbácea. Entre os condicionantes avaliados, destacou-se a curvatura das encostas, presente nas quinze regras de associação, possivelmente, devido as corridas de massa terem sido o tipo de movimento de massa de maior ocorrência no evento estudado. No entanto, nos condicionantes altimétricos e do uso e cobertura da terra, não houve prevalência expressiva das cicatrizes em nenhuma de suas classes, o que indica menor relevância. Conclui-se, assim, que provavelmente a combinação dos condicionantes geomorfométricos, declividade e curvatura, possibilitou a elevada magnitude dos eventos ocorridos na região serrana fluminense em 2011.

Palavras-chave: Deslizamentos; Condicionantes geomorfométricos; Descoberta do conhecimento.

Abstract: Mass movements are slope evolution processes that have physical elements as their main conditioning factors. However, studies on spatial analysis of physiography in conjunction with occurrences require a large volume of data. In this way, automated techniques for knowledge discovery can assist in carrying out these studies. Therefore, the objective of this work is the application of data mining in the discovery of knowledge about the physiographic conditioning factors of mass movements. The study area is the mountainous region of Rio de Janeiro where one of the biggest natural disasters in Brazil occurred in 2011. The Apriori algorithm was applied, which enabled the extraction of rules of association between the 2,200 scars of mass movements in 2011 and the conditioning factors physiographic, consisting of land use and land cover and geomorphometric variables. The rules revealed that the scars prevailed on convergent and concave slopes of mountainous relief, in the altimetric range between 1,000 and 1,200 m, and covered by herbaceous vegetation. Among the evaluated conditions, the curvature of the slopes, present in the fifteen association rules, stood out, possibly due to the mud and debris flows have been the most frequent type of mass movement in the studied event. However, in altimetric conditions and land use and land cover, there was no significant prevalence of scarring in any of its classes, which indicates less relevance. It is 
concluded, therefore, that probably the combination of geomorphometric conditions, slope and curvature, enabled the high magnitude of the events that occurred in the mountainous region of Rio de Janeiro in 2011.

Keywords: Mass movements; Geomorphometric conditioning factors ; Knowledge discovery.

\section{Introdução}

A ocorrência de grandes acumulados de chuva, em janeiro de 2011, na região serrana do estado do Rio de Janeiro, desencadeou um dos maiores eventos de movimentos de massa generalizados do Brasil (DOURADO; ARRAES; SILVA, 2012). A formação de uma nuvem cumulus nimbus, realimentada por umidade proveniente da Amazônia, deflagrou a ocorrência de chuvas localizadas nas cabeceiras dos vales, com intensidade fortíssima e duração de 4,5 h na madrugada de 11 para 12 de janeiro (BANCO MUNDIAL, 2012; CANEDO; EHRLICH; LACERDA, 2011). Ainda de acordo com este relatório, as chuvas torrenciais, que corresponderam a mais de $70 \%$ do valor médio histórico para o mês de janeiro na cidade de Nova Friburgo, atingiram sete municípios, causando a morte de mais de 900 pessoas e afetando mais de 300 mil pessoas.

Os movimentos de massa são processos naturais, relacionados à evolução morfológica das encostas, e consistem no transporte de rocha, detritos e volume de solo ao longo da encosta pela ação gravitacional (HIGHLAND; BOBROWSKY, 2008; FERNANDES; AMARAL, 2003). Em regiões densamente povoadas, os movimentos assumem frequentemente proporções catastróficas, uma vez que os inúmeros cortes, aterros, depósitos de lixo, desmatamentos, modificações na drenagem, entre outras alterações, geram novas relações com as condições naturais associadas à geomorfologia e à geologia (FERNANDES et al., 2001).

Os elementos do meio físico são os principais agentes que contribuem para o desencadeamento de processos erosivos, acompanhados pelos elementos do meio biótico. Na concepção de Fernandes e Amaral (2003), as características geológicas e geomorfológicos recebem destaque por apresentarem feições que atuam como condicionantes e determinam a localização espacial e temporal dos deslizamentos. Estas feições têm sua origem nos processos geológicos e geomorfológicos que atuaram no passado e que ainda atuam nesses locais, que compõem parte da própria dinâmica dos processos naturais.

As características topográficas do terreno são abordadas como condicionantes em diversos estudos sobre movimentos de massa ao redor do mundo (AYALEW; YAMAGISHI; UGAWA, 2004, YAMAGISHI; IWAHASHI, 2004, LEE; MIN, 2001). A declividade, a orientação e a curvatura das encostas exercem forte controle na localização e deflagração de movimentos de massa. Entre elas, de acordo com Fernandes e Amaral (2003), a curvatura das encostas merece destaque, uma vez que a morfologia do relevo define os níveis de convergência hidrológica do terreno.

Em estudo sobre susceptibilidade a movimentos de massa, realizado na região de Niigata, Japão, Ayalew, Yamagishi e Ugawa (2004) afirmam que a influência de condicionantes, como a declividade e a orientação de encostas, na deflagração de movimentos de massa, tem sido amplamente discutida na literatura. No entanto, acrescentam que deve ser dada atenção ao papel das curvaturas horizontais e verticais como deflagradoras destes eventos. Pinho, Francisco e Salgado (2013), em estudo que analisa a morfometria das encostas atingidas pelos eventos de 2011 em Nova Friburgo, verificaram maior incidência de cicatrizes nos trechos das encostas onde havia convergência de fluxo. Estudo realizado por Lee e Min (2001) na província de Yongin, Coréia, com base em 1,4 mil ocorrências, avalia também a relação entre movimentos de massa e a forma das encostas, indicando que a ruptura aumenta nos trechos com tendência à forma côncava.

A curvatura vertical expressa a forma da vertente observada em perfil e está relacionada ao processo de migração e acúmulo de materiais pela ação da gravidade na superfície. A curvatura horizontal expressa a forma da vertente observada em planta e desempenha um papel fundamental para o balanço hídrico, uma vez que define as áreas onde ocorre a concentração de fluxos (VALERIANO, 2008). Ayalew, Yamagishi e Ugawa (2004) afirmam que existe alta tendência a ruptura de uma encosta quando ocorre ao menos uma das formas côncavas, devido à possibilidade de acúmulo de água no solo.

A orientação e a declividade de vertentes possuem uma relação de complementaridade na descrição tridimensional do terreno, que se estendem aos processos de deslocamento de materiais por ação da gravidade, daí a sua importância nos estudos sobre a dinâmica das encostas e os processos de movimentos de massa (VALERIANO, 2008). Trabalhos desenvolvidos por Lee e Min (2001), Dai e Lee (2002) e Ayalew, Yamagishi e 
Ugawa (2004) utilizaram as variáveis topográficas no mapeamento da susceptibilidade e risco de desastres naturais, e reforçaram a importância do papel que exercem, bem como o modo que se combinam, para a compreensão da distribuição espacial dos movimentos de massa.

Devido à forte associação a processos de transporte gravitacional, a declividade é uma variável básica para definição do zoneamento no planejamento territorial. Os métodos de avaliação de terras e planejamento conservacionista, baseados em modelagem numérica, incorporam a variável declividade, além de ter destaque também na interpretação geomorfológica (VALERIANO, 2008). Lee e Min (2001) consideram a declividade uma componente essencial na análise de estabilidade das encostas, pois, conforme o ângulo de inclinação aumenta, a tensão de ruptura no solo se intensifica. $\mathrm{Na}$ análise estatística sobre susceptibilidade a movimentos de massa, realizada por estes autores em Yongin, Coréia, os resultados mostraram que encostas com inclinação superior a $15^{\circ}$ apresentam alta probabilidade de ruptura, enquanto gradientes mais baixos estão associados a tensões de ruptura menores.

A elaboração de mapas de susceptibilidade requer conhecimento a respeito dos fatores condicionantes da ocorrência movimentos de massa. Neste sentido, Ayalew, Yamagishi e Ugawa (2004) realizaram análise em Niigata, Japão, através do método de combinação linear com sobreposição de mapas com os parâmetros topográficos derivados de um Modelo Digital de Elevação (MDE), o mapa de geologia e um banco de dados com 791 escorregamentos. Os autores concluem o estudo afirmando que mapas de suscetibilidade a movimentos de massa com maior acurácia dependem da identificação do papel que os condicionantes geomorfológicos exercem na sua deflagração. Estudo semelhante foi realizado por Gonçalves e Francisco (2016) na área atingida pelas fortes chuvas de 2011 na região serrana fluminense. A sobreposição das 2,2 mil cicatrizes às condicionantes topográficas indicou à importância das variáveis geomorfométricas na ocorrência dos movimentos de massa, pois os trechos das encostas convergentes e com declividade entre $10^{\circ}$ e $30^{\circ}$ foram os mais atingidos pelos movimentos de massa nos eventos de 2011.

É comum a utilização de inventários de movimentos de massa e relatórios técnicos na análise espacial entre os condicionantes e as cicatrizes dos movimentos de massa em estudos para a identificação das características do ambiente no local onde os movimentos de massa ocorrem. Chagas, Chan e Corsi (2010), que realizaram estudo com aplicação de técnicas de mineração de dados em deslizamentos, afirmam que o processo de interpretação dos dados pode ser uma tarefa lenta e subjetiva à medida que o volume dos dados aumenta e a capacidade de análise diminua. Neste sentido, a aplicação de um processo de análise automatizado, como a mineração de dados, pode auxiliar na compreensão do modo como os elementos do meio físico e a ação antrópica se relacionam com a ocorrência de desastres naturais.

A mineração de dados corresponde a uma tecnologia que compõe as etapas da Descoberta de Conhecimento em Bases de Dados (KDD - Knowledge Discovery from Data). Han, Kamber e Pei (2012) afirmam que KDD consiste em um processo interativo e iterativo, envolvendo algumas etapas, entre elas a mineração de dados, considerada fundamental dentro do processo KDD por revelar padrões ocultos no conjunto de dados. Entre as técnicas de mineração de dados, as regras de associação objetivam descobrir padrões de associação desconhecidos em bases de dados através do uso de algoritmos que atuam na extração de conjuntos de atributos frequentes inseridos em um conjunto maior, buscando expor tendências para determinar relações entre conjuntos de itens que apresentam como vantagem a facilidade no uso (CHAGAS; CHAN; CORSI, 2010).

Desta forma, o presente trabalho tem como objetivo a realização da mineração de dados, com aplicação do algoritmo de extração de regras de associação, para a descoberta de padrões de ocorrência entre os condicionantes, uso e cobertura da terra e os geomorfológicos, e as cicatrizes dos movimentos de massa, desencadeados pelas fortes chuvas que atingiram a região serrana do estado do Rio de Janeiro em de janeiro de 2011.

A área em estudo abrange a bacia do alto curso do rio Grande, com área de $336 \mathrm{~km}^{2}$, e está localizada na porção setentrional do município de Nova Friburgo, estendendo-se pelos distritos de Nova Friburgo, Campo do Coelho e Rio Grandina (Figura 1). Esta está inserida na unidade geomorfológica Escarpa das Serras do Couto e dos Órgãos, caracterizada por apresentar relevo acidentado com vertentes íngremes e predomínio de encostas com formas côncavas e retilíneas (DANTAS, 2001). O clima predominante é tropical de altitude, com temperatura média anual de $16^{\circ} \mathrm{C}$ e um dos maiores índices pluviométricos do estado fluminense, $2.500 \mathrm{~mm}$ nas áreas de maior altitude (COELHO NETTO et al., 2011). O núcleo urbano de Nova Friburgo encontra-se em alvéolo localizado na bacia hidrográfica do rio Bengalas, afluente do rio Grande. Em alvéolo de relevo mais suave, encontra-se a localidade de Campo do Coelho, parte do cinturão verde de produção de horticultura da região serrana do estado. 


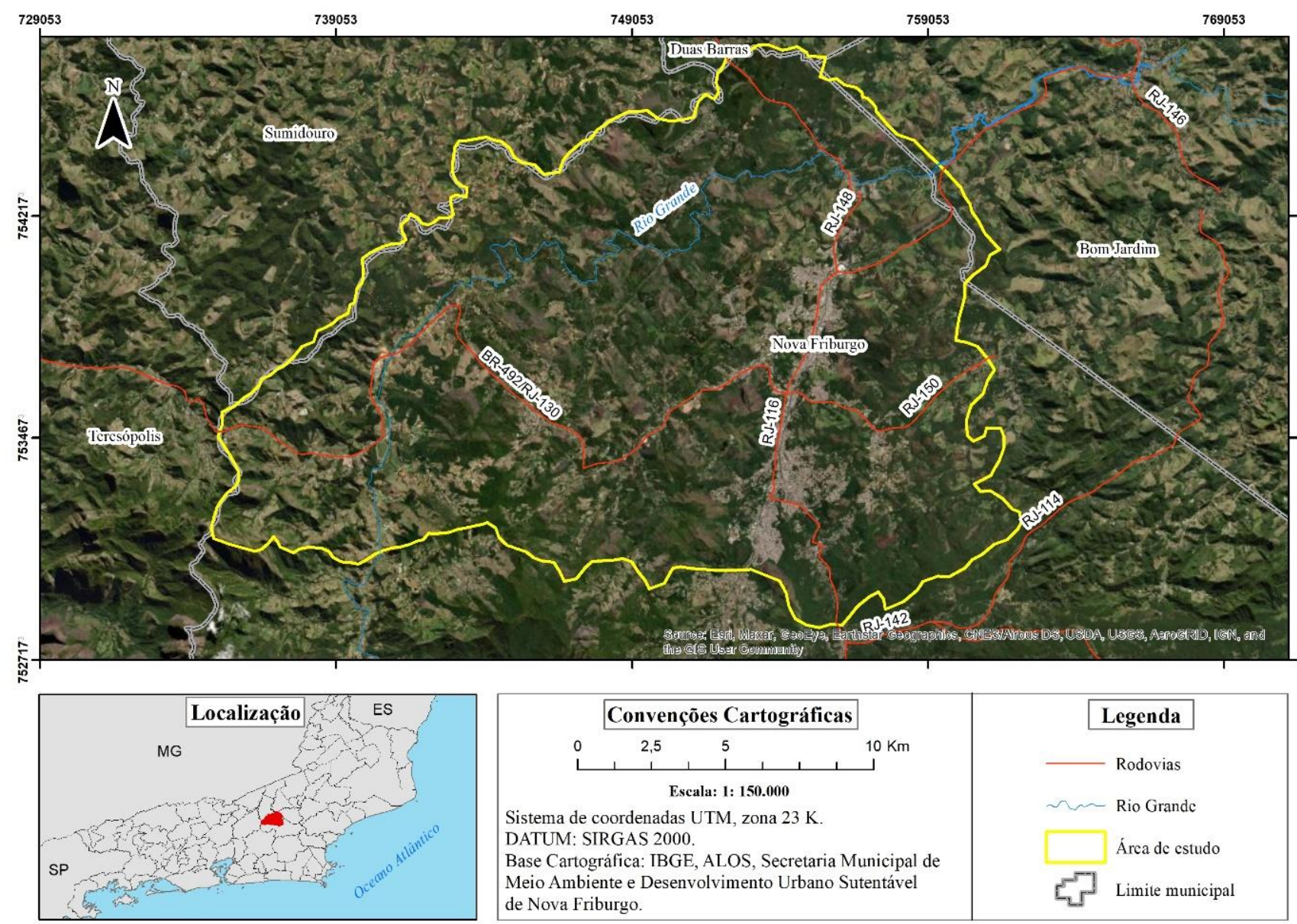

Figura 1: Localização do alto curso da bacia do rio Grande, Nova Friburgo, RJ.

\section{Materiais e Métodos}

O trabalho foi desenvolvido em três etapas: $1^{a}$. geração da base de dados dos condicionantes fisiográficos; $2^{a}$. mineração dos dados para geração das regras de associação, e $3^{3}$. validação das regras de associação (Figura 2).

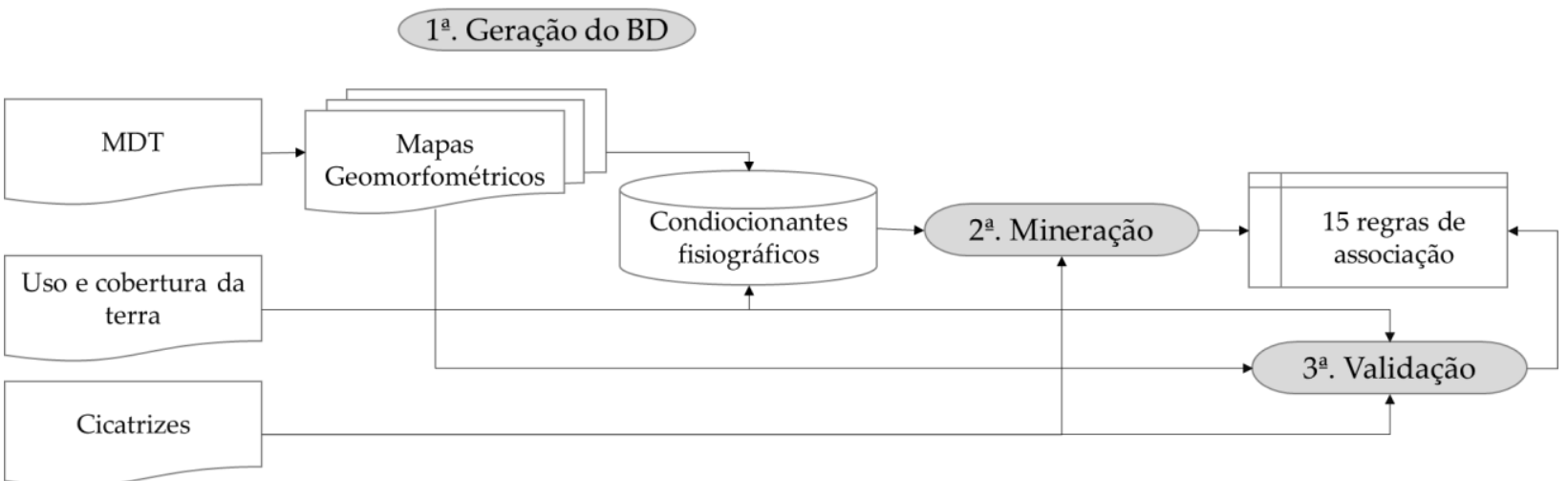

Figura 2: Fluxograma das etapas de trabalho.

A primeira etapa do trabalho, consistiu na geração da base de dados dos condicionantes constituída pelos mapas geomorfométricos - altimetria, declividade, curvatura vertical e curvatura horizontal das vertentes, e uso e cobertura da terra.

Os mapas geomorfométricos foram gerados a partir do Modelo Digital de Terreno (MDT) com resolução espacial de $5 \mathrm{~m}$. O modelo foi obtido pela interpolação das curvas de nível, equidistância de $10 \mathrm{~m}$, e da rede de drenagem, ambas oriundas da Base Cartográfica Vetorial Contínua do Estado do Rio de Janeiro, na escala 1:25.000, oriundas da restituição de fotografias aéreas na escala aproximada de 1:30.000 pelo IBGE (2018). Como interpolador, foi utilizado o algoritmo ANUDEM, implementado na extensão 3D Analyst ArcGIS® como 
TopoToRaster, que consiste em um método especificamente projetado para criar modelos digitais hidrologicamente corrigidos (ESRI, 2020). Este algoritmo, desenvolvido por Hutchinson (1989), interpola dados de elevação em uma grade regular minimizando a rugosidade e removendo as depressões espúrias do terreno, considerando as restrições atribuídas pelas linhas de drenagem, depressões e lagos.

A seguir, foram definidas as classes dos mapas geomorfométricos de acordo com as proposições presentes literatura pertinente. Esta etapa é necessária pois estes mapas são gerados em grades contínuas, enquanto o algoritmo de mineração necessita que os dados sejam discretos.

A declividade foi classificada, de acordo com EMBRAPA (1999), nas seguintes classes de relevo: Plano (0 a $3 \%$ ), Suave ondulado (3 a 8\%), Ondulado (8 a 20\%), Forte ondulado (20 a 45\%), Montanhoso (45 a 75\%) e Escarpado (> 75\%). Nos mapas de curvatura horizontal e curvatura vertical, as classes foram definidas segundo Valeriano (2008). Para a curvatura horizontal, foram definidas, como Planares, as encostas com intervalo entre $-0,038 \% \mathrm{~m}$ e $+0,051 \% \mathrm{~m}$, enquanto os valores menores a $-0,038 \% \mathrm{~m}$ como Convergentes e, como Divergentes, valores maiores a $+0,051 \% \mathrm{~m}$. No mapa de curvatura vertical, foram definidas, como Retilíneas, as encostas com intervalo entre 0,010\% $\mathrm{m}$ e $+0,010 \% \mathrm{~m}$, enquanto valores menores a $-0,010 \% \mathrm{~m}$ como Côncavas e, como Convexas, valores maiores a $+0,010 \% \mathrm{~m}$. Por fim, a altimetria foi classificada oito classes com intervalos de $200 \mathrm{~m}$.

O mapa de uso e cobertura da terra utilizado neste trabalho foi confeccionado por Francisco e Almeida (2012) e Garcia e Francisco (2013) através da Análise de Imagem Baseada em Objetos Geográficos (GEOBIA - Geographic Object-Based Image Analysis), que consiste na utilização de descritores topológicos, texturais e espectrais, na classificação automática dos objetos com base em uma rede semântica, simulando, assim, a interpretação humana. De acordo com as autoras, foram utilizadas quatro bandas multiespectrais do ALOS/AVNIR-2 - azul, verde, vermelha e infravermelha, com $10 \mathrm{~m}$ de resolução espacial, fusionadas à pancromática do ALOS/PRISM, com 2,5 $\mathrm{m}$, obtidas em 2009. O mapa final, com resolução espacial de $2,5 \mathrm{~m}$, apresentou as seguintes classes: floresta, vegetação herbácea, reflorestamento, queimada, afloramento rochoso, ocupação urbana.

Por fim, o mapeamento das cicatrizes dos movimentos de massa ocorridos em 2011 foi elaborado pela Secretaria Municipal de Meio Ambiente de Nova Friburgo, através da interpretação visual das imagens GeoEye, disponíveis no Google Earth em conjunto com imagens GeoEye cedidas pelo INPE, obtidas em 19 de janeiro de 2011, ou seja, oito dias após o evento pluviométrico. Foram mapeadas 2.191 cicatrizes, com área total de 14,6 km², que representa $4,3 \%$ da área de estudo. As cicatrizes foram identificadas por manchas de solo exposto com forma alongada longitudinalmente às encostas incorporando toda a extensão da área movimentada.

As classes dos mapas condicionantes, a seguir, foram discretizadas por rótulo numérico necessário para adequar os dados à formato nominal, estrutura suportada pelo algoritmo de mineração de dados aqui utilizado. A base de dados utilizada para a extração das regras de associação foi, assim, constituída por uma tabela com a moda das classes dos mapas (coluna) de cada cicatriz (linha), obtida através da análise estatística resultante da sobreposição entre as cicatrizes e os condicionantes.

Com a base de dados concluída, a segunda etapa consistiu na mineração de dados com objetivo de descobrir padrões de associação através da extração de atributos frequentes inseridos em um conjunto maior. A extração das regras de associação foi realizada com Apriori, disponível no programa WEKA (Waikato Environment for Knowledge Analysis), desenvolvido na Universidade de Waikato, Nova Zelândia, que contém algoritmos de aprendizagem de máquina para o pré-processamento, transformação, mineração de dados e validação de resultados (SILVA, 2016).

A regra de associação possui o formato $A=>B$, onde $A$, chamado de antecedente, e $B$, de consequente, são conjuntos de itens, atributos ou transações, em que atributo A implica no atributo B (AGRAWAL; SRIKANT, 1994). Para a avaliação das regras geradas, são usadas as medidas suporte e confiança. O suporte é definido como a fração de itens que satisfazem o conjunto A e B na regra. Se o suporte não for suficiente, significa que a regra não é digna de ser usada ou que pode ser avaliada mais tarde. A confiança é uma medida de força de suporte da regra. Pode ser vista como a possibilidade de encontrar B nas transações com a condição de que estas também contenham A. Ainda de acordo com os mesmos autores, a tarefa de descobrir regras de associação se divide em duas etapas, na qual a primeira consiste em encontrar todos os conjuntos de itens frequentes que satisfaçam o suporte mínimo (largeitensets), entendido como o número de transações que contém este conjunto. A segunda etapa corresponde ao uso dos conjuntos de itens frequentes obtidos para gerar as regras de associação na base de dados.

Foram realizados testes com combinações entre os condicionantes e os valores de suporte máximo, até que fossem geradas as regras que revelassem, de acordo com o algoritmo Apriori, conhecimento relevante sobre a 
análise entre os movimentos de massa e os condicionantes geomorfométricos e de uso e cobertura da terra no evento ocorrido na região serrana fluminense em janeiro de 2011.

Por fim, a terceira etapa consistiu na validação das regras de associação geradas pelo algoritmo Apriori, e foi feita através da análise da distribuição espacial das cicatrizes pelos condicionantes. Para isto, foi feito o cálculo da razão entre a área das cicatrizes ( $\mathrm{ACi}$ ) presentes em cada classe temática e a área da respectiva classe (ACl), o que resultou na área relativa (\%) das cicatrizes por cada classe temática.

\section{Resultados}

Os testes realizados com algoritmo Apriori para a descoberta de padrões de associação entre os condicionantes geomorfométricos e de uso e cobertura com as cicatrizes de movimentos de massa indicaram que, para a geração das regras de associação, era necessário estabelecer um suporte mínimo de 0,75 , pois, abaixo deste valor, não foram criadas regras de associação. Desta forma, foram aplicados valores entre 0,7 e 0,75 resultando na geração de quinze regras de associação, ou seja, a associação deve ocorrer em pelo menos em $70 \%$ dos casos para ser utilizada na geração das regras de associação (Tabela 1).

Tabela 1. Regras de associação entre cicatrizes de movimentos de massa e os seus condicionantes.

\begin{tabular}{|c|c|c|c|c|c|c|}
\hline \multicolumn{3}{|c|}{ Atributo A } & Ocorrências & Atributo B & Ocorrências & Confiança \\
\hline $\begin{array}{c}\text { Rel. } \\
\text { montanhoso }\end{array}$ & $\begin{array}{c}\mathrm{CH} . \\
\text { convergente }\end{array}$ & - & 838 & $\begin{array}{c}\mathrm{CV} . \\
\text { côncava }\end{array}$ & 628 & \multirow{2}{*}{0,75} \\
\hline $\begin{array}{c}\text { Rel. } \\
\text { montanhoso }\end{array}$ & $\begin{array}{c}\mathrm{CH} . \\
\text { convergente }\end{array}$ & $\begin{array}{c}\text { Alt. } \\
1000-1200 \mathrm{~m}\end{array}$ & 545 & $\begin{array}{c}\text { CV. } \\
\text { côncava }\end{array}$ & 407 & \\
\hline $\begin{array}{c}\text { Alt. } \\
800 \text { a } 100 \text { m }\end{array}$ & - & - & 666 & $\begin{array}{l}\text { CV. } \\
\text { côncava }\end{array}$ & 496 & \multirow{3}{*}{0,74} \\
\hline $\begin{array}{c}\mathrm{CH} . \\
\text { convergente }\end{array}$ & - & - & 1420 & $\begin{array}{c}\mathrm{CV} . \\
\text { côncava }\end{array}$ & 1049 & \\
\hline $\begin{array}{c}\text { Uso. } \\
\text { herbácea }\end{array}$ & $\begin{array}{c}\mathrm{CH} . \\
\text { convergente }\end{array}$ & - & 722 & $\begin{array}{l}\text { CV. } \\
\text { côncava }\end{array}$ & 533 & \\
\hline $\begin{array}{c}\text { Uso. } \\
\text { herbácea }\end{array}$ & $\begin{array}{c}\text { Rel. } \\
\text { montanhoso }\end{array}$ & - & 602 & $\begin{array}{c}\text { CV. } \\
\text { côncava }\end{array}$ & 442 & \multirow{2}{*}{0,73} \\
\hline $\begin{array}{c}\text { Uso. } \\
\text { herbácea }\end{array}$ & $\begin{array}{c}\mathrm{CH} . \\
\text { convergente }\end{array}$ & $\begin{array}{c}\text { Alt. } \\
1000-1200 \mathrm{~m}\end{array}$ & 504 & $\begin{array}{l}\mathrm{CV} . \\
\text { côncava }\end{array}$ & 369 & \\
\hline $\begin{array}{c}\text { Uso. } \\
\text { herbácea }\end{array}$ & $\begin{array}{c}\text { CV. } \\
\text { côncava }\end{array}$ & $\begin{array}{c}\text { Alt. } \\
1000-1200 \mathrm{~m}\end{array}$ & 510 & $\begin{array}{c}\mathrm{CH} . \\
\text { convergente }\end{array}$ & 369 & \multirow{3}{*}{0,72} \\
\hline $\begin{array}{l}\text { Uso. } \\
\text { floresta }\end{array}$ & $\begin{array}{c}\mathrm{CH} . \\
\text { convergente }\end{array}$ & - & 567 & $\begin{array}{l}\text { CV. } \\
\text { côncava }\end{array}$ & 409 & \\
\hline $\begin{array}{c}\mathrm{CH} . \\
\text { convergente }\end{array}$ & $\begin{array}{c}\text { Alt. } \\
1000-1200 \mathrm{~m}\end{array}$ & - & 909 & $\begin{array}{l}\text { CV. } \\
\text { côncava }\end{array}$ & 652 & \\
\hline $\begin{array}{c}\text { Rel. } \\
\text { montanhoso }\end{array}$ & $\begin{array}{c}\mathrm{CV} . \\
\text { côncava }\end{array}$ & $\begin{array}{c}\text { Alt. } \\
1000-1200 \mathrm{~m}\end{array}$ & 289 & $\begin{array}{c}\mathrm{CH} . \\
\text { convergente }\end{array}$ & 407 & \multirow{5}{*}{0,71} \\
\hline $\begin{array}{c}\mathrm{CV} . \\
\text { côncava }\end{array}$ & $\begin{array}{c}\text { Alt. } \\
1000-1200 \mathrm{~m}\end{array}$ & - & 915 & $\begin{array}{c}\mathrm{CH} . \\
\text { convergente }\end{array}$ & 652 & \\
\hline $\begin{array}{c}\text { Uso. } \\
\text { herbácea }\end{array}$ & $\begin{array}{c}\text { Alt. } \\
1000-1200 \mathrm{~m}\end{array}$ & - & 717 & $\begin{array}{c}\text { CV. } \\
\text { côncava }\end{array}$ & 510 & \\
\hline $\begin{array}{c}\text { Uso. } \\
\text { herbácea }\end{array}$ & - & - & 1085 & $\begin{array}{l}\text { CV. } \\
\text { côncava }\end{array}$ & 770 & \\
\hline $\begin{array}{c}\text { Rel. } \\
\text { montanhoso }\end{array}$ & - & - & 1285 & $\begin{array}{l}\mathrm{CV} . \\
\text { côncava }\end{array}$ & 910 & \\
\hline
\end{tabular}

Nota: Rel. $=$ Relevo; Alt. $=$ Altitude; CV. $=$ Curvatura Vertical; $C H .=$ Curvatura Horizontal; Uso. $=$ Uso e Cobertura da Terra.

A primeira regra, com suporte mínimo de 0,75 , explicitou a relação entre relevo montanhoso e curvatura horizontal convergente, com a ocorrência de 838 casos de cicatrizes, associados à curvatura vertical côncava em 628 cicatrizes. A segunda regra, com suporte mínimo de igual valor, identificou 545 ocorrências em relevo montanhoso, curvatura horizontal convergente e altitude entre 1.000 a $1.200 \mathrm{~m}$, com 407 casos localizados em curvatura vertical côncava.

Com 0,74 de suporte mínimo, a regra seguinte explicitou que em 1.420 ocorrências mapeadas como de curvatura horizontal convergente, 1.049 estão associadas com a curvatura vertical côncava. Também com suporte de mesmo valor, a classe de uso e cobertura da terra herbácea ocorreu associada à curvatura horizontal convergente em 722 ocorrências, implicando em curvatura vertical côncava em 533 delas. 
Foram geradas duas regras com suporte igual a 0,73. Em 602 ocorrências, foi registrada a associação entre a classe de uso e cobertura da terra herbácea e relevo montanhoso, implicando em curvatura vertical côncava em 442 casos. A regra seguinte descreve padrão entre a classe herbácea, a curvatura horizontal convergente e altitude entre 1.000 e 1.200 m em 504 cicatrizes, com implicação em encostas com curvatura vertical côncava em 369 casos.

As três regras seguintes apresentaram suporte mínimo de 0,72 . A classe de uso e cobertura da terra floresta esteve presente na nona regra associada à curvatura horizontal convergente em 567 cicatrizes com implicação em curvatura vertical côncava em 409 ocorrências. A décima regra apresenta em 909 ocorrências com associação entre altitude de 1.200 a $1.400 \mathrm{~m}$ e curvatura horizontal convergente, implicando em curvatura vertical côncava em 652 casos. A próxima regra há associação entre relevo montanhoso, a curvatura horizontal convergente e a altitude entre 1.200 e 1.400 m em 570 casos, implicando em 407 ocorrências com curvatura vertical tendendo a côncava.

Por fim, o suporte de 0,71 resultou em quatro regras. Foi apresentado padrão de associação entre curvatura vertical côncava e altitude de 1.200 a 1.400 m registrado em 920 ocorrências, implicando em curvatura horizontal convergente em 650 delas. A classe herbácea ocorreu associada a altitude entre 1.200 e $1.400 \mathrm{~m}$ em 717 casos, implicando em curvatura horizontal côncava em 517 cicatrizes. A classe herbácea também ocorreu em 1.085 cicatrizes implicando em curvatura vertical côncava em 770 ocorrências. Por fim, a última regra gerada pela mineração de dados descreve um padrão em que o relevo montanhoso ocorre em 1.285 cicatrizes implicando em curvatura vertical côncava em 910 ocorrências.

As regras criadas pela mineração de dados com os condicionantes geomorfométricos e uso e cobertura da terra das cicatrizes identificaram a importância da forma das encostas na ocorrência dos movimentos de massa em 2011 na região serrana fluminense. Em todas as regras de associação geradas, a curvatura das encostas estava presente, sendo que em doze delas estava incluída a curvatura vertical côncava e, em dez, a curvatura horizontal convergente. Possivelmente, esta relevância pode ser explicada pelo fato das encostas côncavas e convergentes serem zonas de concentração dos fluxos e, as corridas de massa ter sido um dos principais tipos de movimentos de massa ocorridos em 2011 na região serrana (DRM, 2011).

A análise espacial da distribuição corrobora os resultados alcançados com a mineração. Verifica-se que as cicatrizes, $64 \%$, predominam na classe côncava do mapa de curvatura vertical, que corresponde a $23 \%$ da superfície da bacia, desta forma, em 13\% da classe côncava, há a presença de cicatrizes (Figura 3). As demais classes de curvatura vertical totalizam $77 \%$ da área de estudo, no entanto apenas $36 \%$ da área das cicatrizes aí ocorrem, ou seja, $4 \%$ destas classes estavam ocupadas por cicatrizes. 


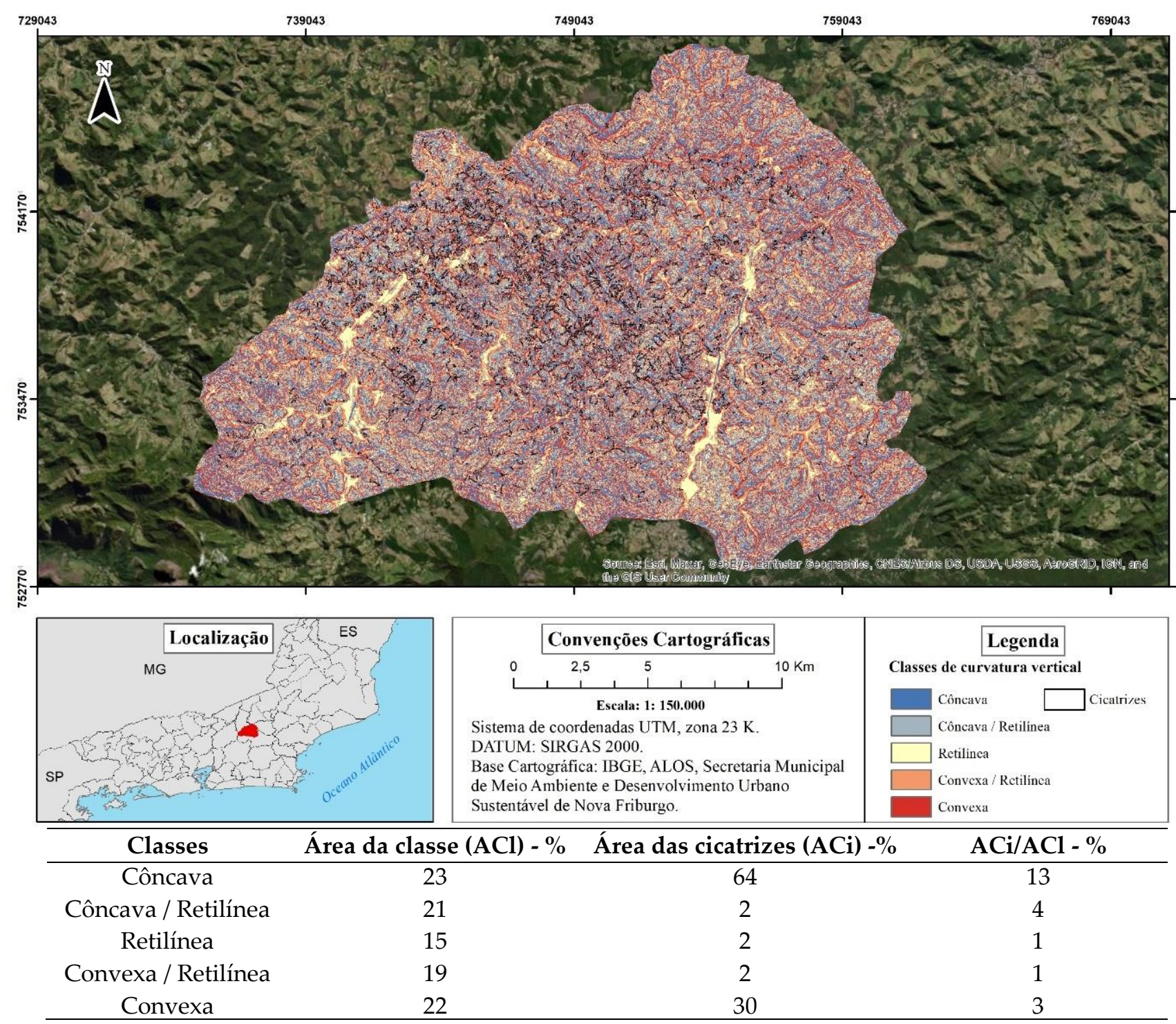

Figura 3: Distribuição espacial das cicatrizes de acordo com a curvatura vertical do alto curso da bacia do rio Grande, Nova Friburgo, RJ. 
As cicatrizes, $65 \%$, também predominam na classe convergente da curvatura horizontal, que representa $28 \%$ da área de estudo, desta forma, em 14\% da classe convergente, as cicatrizes estão aí localizadas (Figura 4). As encostas divergentes, no entanto, com 39\% da área de estudo, e concentram $30 \%$ da área das cicatrizes, ou seja, em $5 \%$ desta classe, ocorrem as cicatrizes. As demais classes representam $33 \%$ da área de estudo e concentram apenas $5 \%$ das cicatrizes.

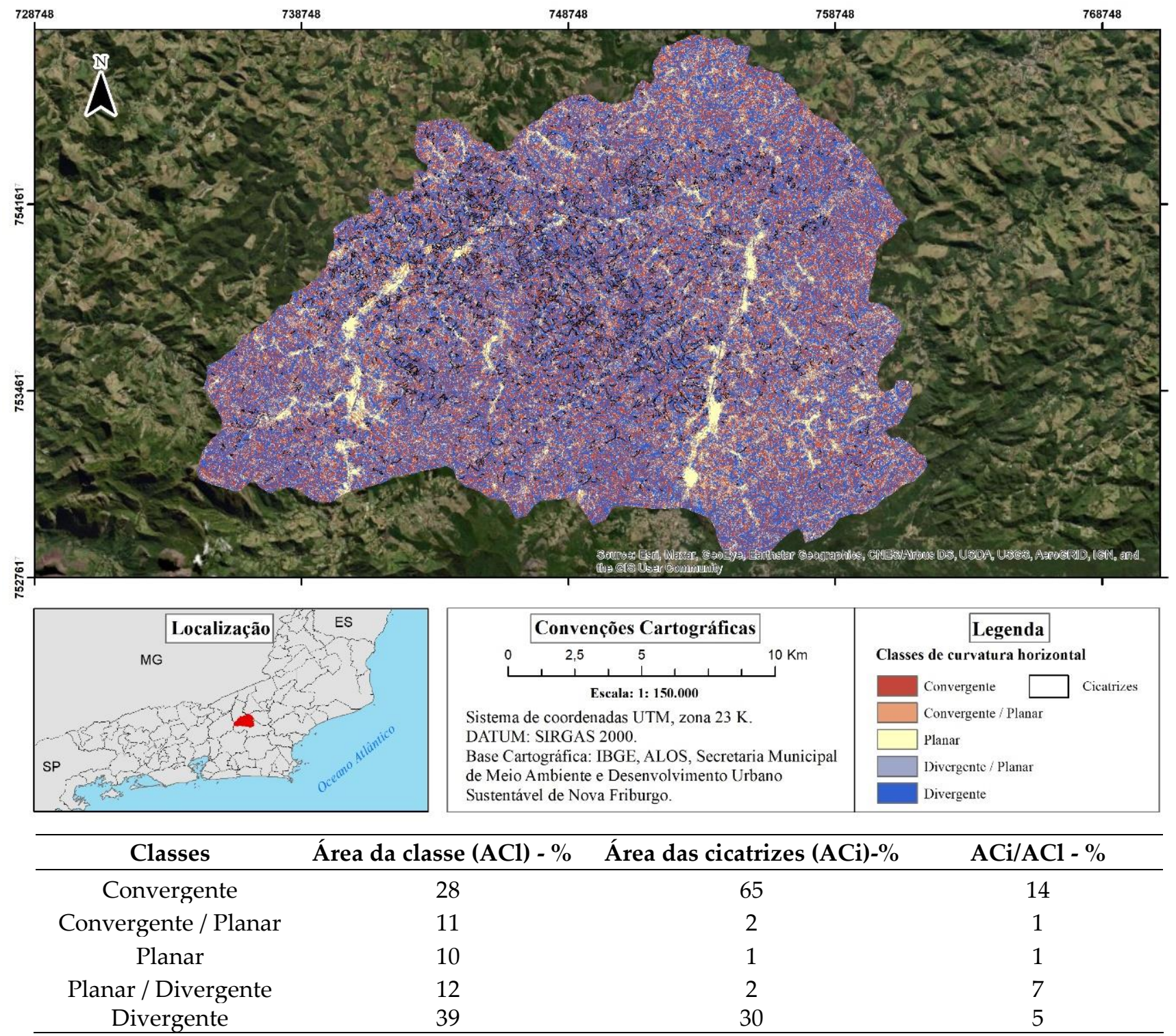

Figura 4: Distribuição espacial das cicatrizes de acordo com a curvatura horizontal do alto curso da bacia do rio Grande, Nova Friburgo, RJ.

O papel da forma do terreno como condicionante de movimentos de massa tem sido discutido em trabalhos como de Pinho, Francisco e Salgado (2013), Fernandes et al. (2001) e Ayalew, Yamagishi e Ugawa (2004). As encostas côncavas ou convergentes proporcionam a concentração máxima dos fluxos hidrológicos, o que facilita o acúmulo de água no solo e, consequentemente, aumento da poro-pressão. De acordo com Ayalew e Yamagishi (2004), em estudos realizados na bacia do Nilo Azul, Etiópia, as corridas de lama e deslizamentos rotacionais são comuns em encostas côncavas, enquanto os translacionais ocorrem principalmente nas planares, no entanto eles atingem grande extensão e profundidade, quando ocorrem nas encostas convexas.

Em relação à declividade, a única classe presente nas regras de associação foi o relevo montanhoso incluído em cinco regras. A análise espacial da distribuição das cicatrizes pelas classes de declividade mostra que a maior parte das ocorrências, $58 \%$, se situa em relevo montanhoso (declividade entre $24^{\circ}$ e 37 ), que corresponde a $34 \%$ da área de estudo, ou seja, em $11 \%$ da área desta classe, as cicatrizes estão presentes (Figura 5). Com exceção do relevo 
escarpado, onde $12 \%$ da área estão cobertas por cicatrizes, no entanto representam apenas $15 \%$ da sua área total, nas demais classes, estão presentes em menos de 3\% e, no relevo plano, não há ocorrências.

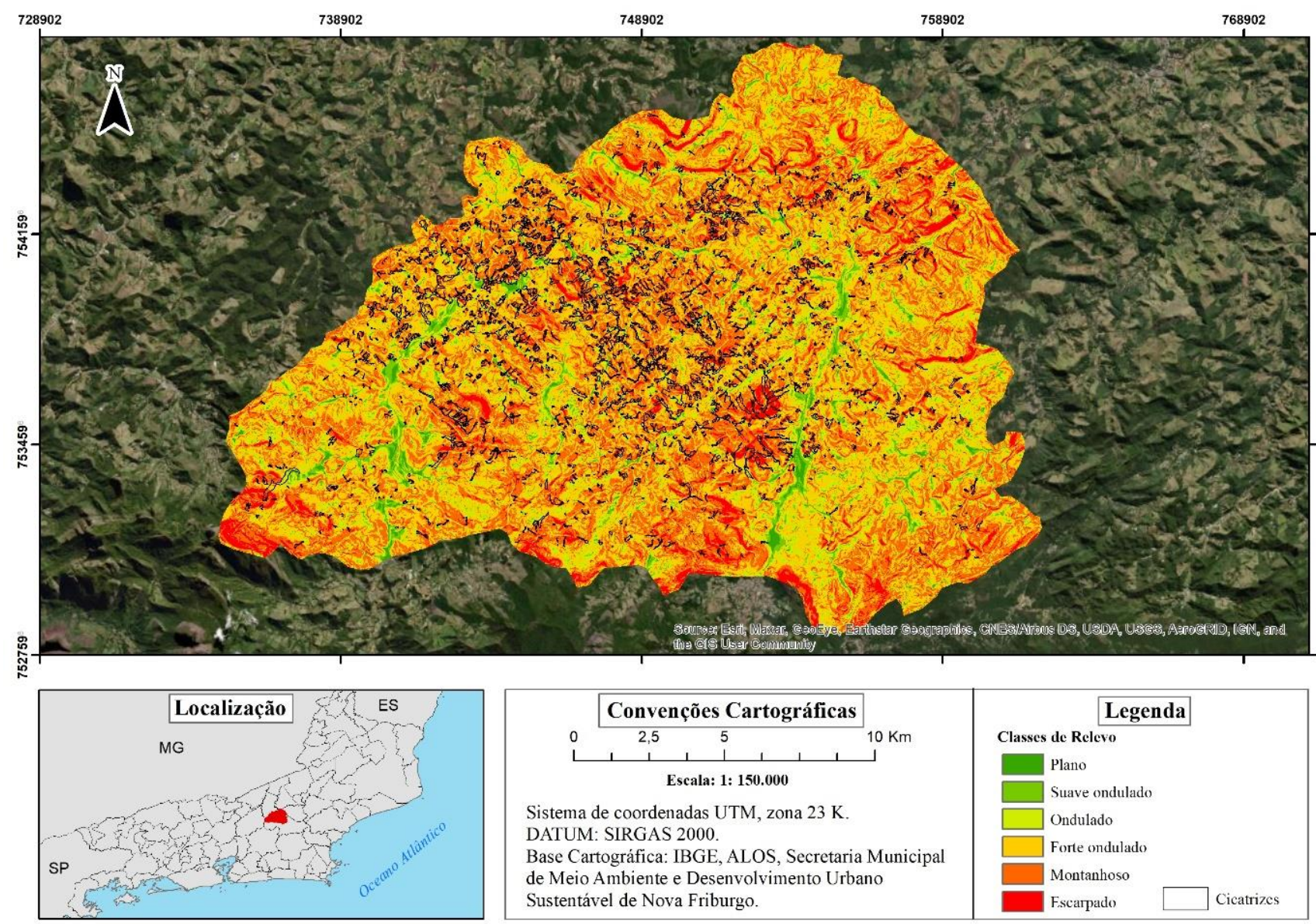

\begin{tabular}{cccc}
\hline Classes & Área da classe (ACl) - \% & Área das cicatrizes (ACi)-\% & ACi/ACl - \% \\
\hline Plano & 1 & 0 & 0 \\
Suave ondulado & 4 & 1 & 1 \\
Ondulado & 13 & 5 & 2 \\
Forte ondulado & 38 & 21 & 3 \\
Montanhoso & 34 & 58 & 11 \\
Escarpado & 10 & 15 & 12 \\
\hline
\end{tabular}

Figura 5: Distribuição espacial das cicatrizes de acordo com a declividade do alto curso da bacia do rio Grande, Nova Friburgo, RJ.

Os resultados aqui obtidos confirmam o que tem sido discutido pela literatura científica a respeito da influência exercida pela declividade no aumento da tensão de ruptura das encostas à medida que o ângulo de inclinação aumenta. O trabalho de Francisco (1996), com base no estudo de 67 cicatrizes oriundas de eventos ocorridos em 1966 e 1988 no Maciço da Tijuca, identificou que 50\% das ocorrências concentravam-se em encostas com declividade entre $25^{\circ}$ e $45^{\circ}$. Avelar et al. (2011), analisando 3,6 mil cicatrizes, corrobora a importância das classes intermediárias de declividade, ao verificar que a maior parte dos movimentos de massa ocorreu em inclinações superiores a $21^{\circ}$ nos eventos da região serrana em 2011. Regmi, Giardino e Vitek, ao analisar 735 cicatrizes no Colorado, EUA, observaram que as cicatrizes predominavam entre $15^{\circ}$ e $40^{\circ}$. Nesse mesmo sentido, Fernandes et al. (2001), ao testar modelos matemáticos no Maciço da Tijuca, constataram que maior ocorrência de movimentos de massa era observado com aumento do gradiente da encosta em valores extremos entre $37^{\circ}$ e $55^{\circ}$.

No tocante à altimetria, verifica-se que esteve presente em nove das quinze regras. A classe entre $1.000 \mathrm{e} 1.200$ m foi incluída em oito regras de associação e a classe de 600 a $800 \mathrm{~m}$ em uma. A análise da distribuição espacial indica que a maior parte das cicatrizes, $60 \%$, se situa entre 1.000 e $1.200 \mathrm{~m}$, com $39 \%$ da área estudo, o que resulta em $6 \%$ da respectiva classe estar com a presença das cicatrizes. (Figura 6). As faixas restantes, com $40 \%$ das Revista Brasileira de Geomorfologia. 2021, v. 22, n. 4; (Out-Dez) DOI: 10.20502/rbg.v22i4.1982 
cicatrizes e que representam $51 \%$ da área de estudo, possuem menos de $7 \%$ ocupadas com cicatrizes. O valor máximo da razão entre as cicatrizes $(\mathrm{ACi})$ e a classe temática $(\mathrm{ACl})$ para a altimetria é menor entre os demais condicionantes até aqui analisados cujos máximos variam entre $14 \%$ a $11 \%$.

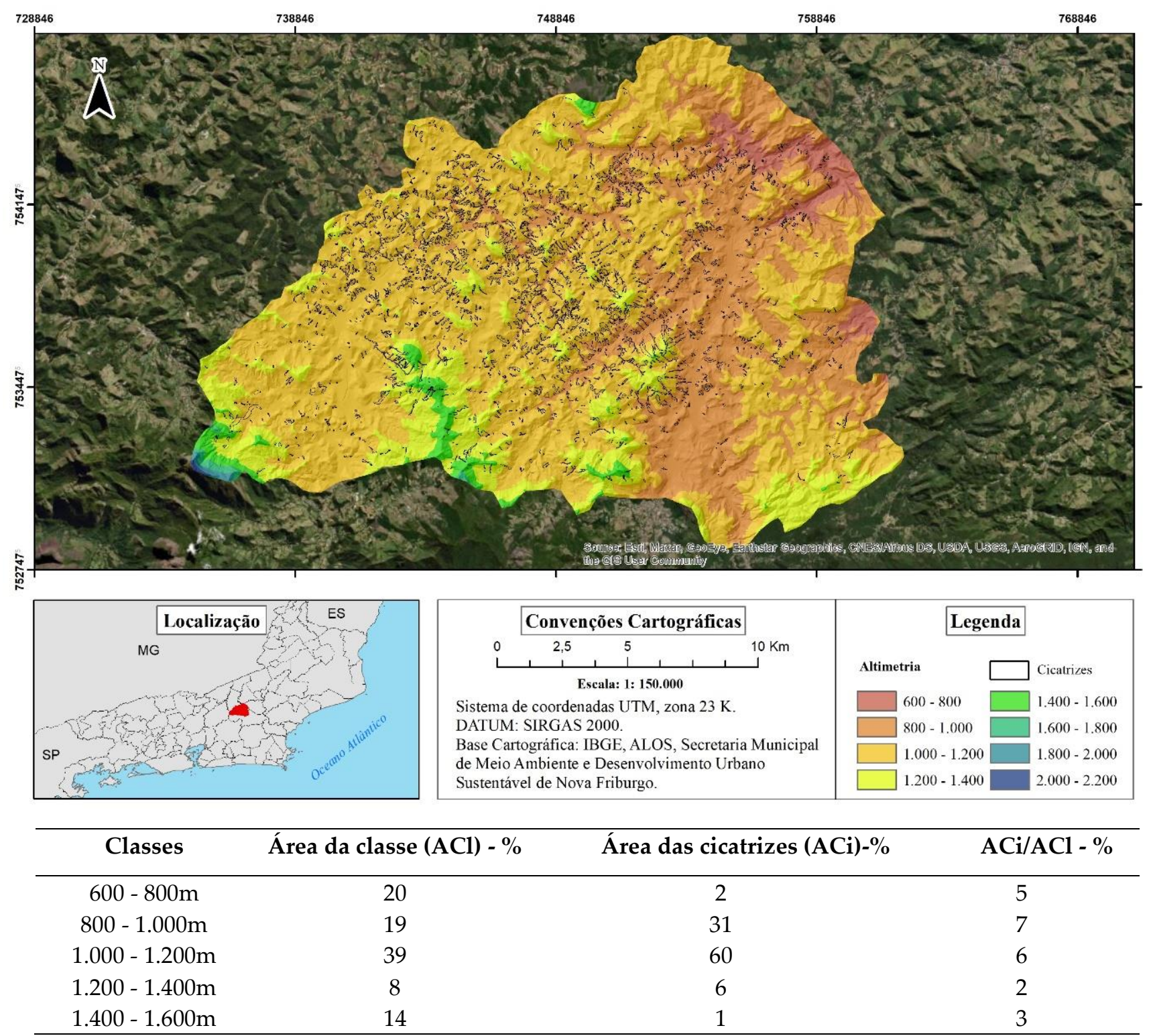

Figura 6: Distribuição espacial das cicatrizes de acordo com a altimetria do alto curso da bacia do rio Grande, Nova Friburgo, RJ.

Coelho Netto et al. (2011), em trabalho realizado na região serrana fluminense, apontaram a relevância da altimetria ao identificar que $55 \%$ dos deslizamentos ocorreram em topos de morro e porções mais elevadas das encostas. Segundo os autores, os moradores entrevistados confirmaram a ocorrência de intensos raios e trovoadas atingindo os topos das elevações, durante a tempestade entre 11 e 12 de janeiro de 2011, que reforçam as ideias sobre a associação entre raios e o desencadeamento dos movimentos de massa durante fortes tempestades de verão. Enquanto o trabalho de Pinho, Francisco e Salgado (2013), realizado na bacia do Córrego Dantas, também na região serrana fluminense, constatou que $25 \%$ das cicatrizes analisadas atingiam os topos de morros.

As classes de uso e cobertura da terra presentes nas regras de associação foram herbácea e floresta, a primeira esteve presente em cinco regras e a última em apenas uma. Análise espacial das ocorrências de movimentos de massa também mostra que as cicatrizes, $90 \%$, se concentram nas respectivas classes, que possuem $85 \%$ da área de estudo, o que resulta em 6\% da área de florestas e herbácea afetadas pelos movimentos (Figura 7). Nas classes restantes, com $15 \%$ da área de estudo, estão $10 \%$ das cicatrizes, ou seja, o que representa menos de $5 \%$ da área de 
cada classe. Assim como a altimetria, o valor máximo da razão entre as cicatrizes (ACi) e a classe temática (ACl) para o uso e cobertura da terra também é menor, $6 \%$, entre os demais condicionantes.

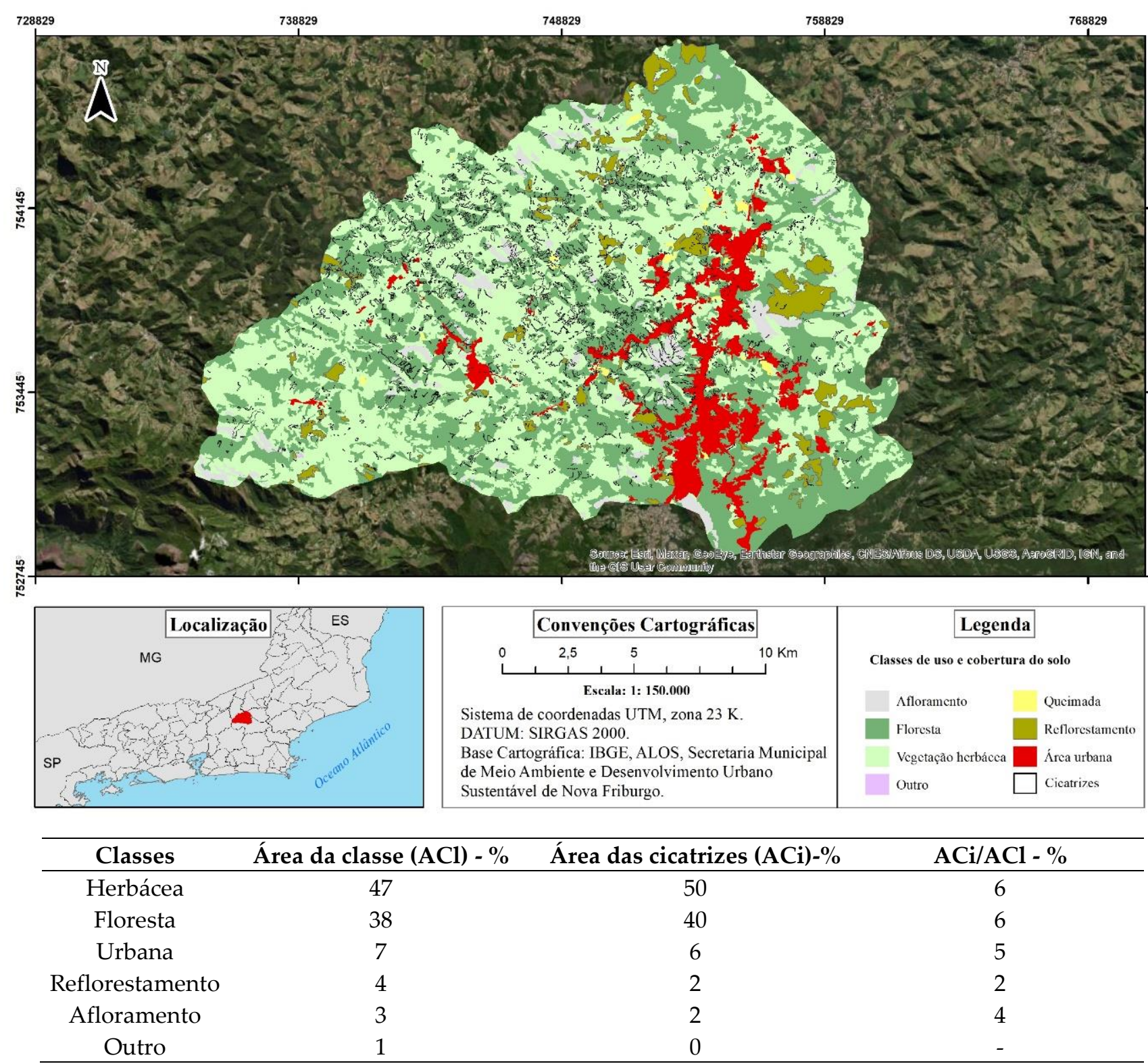

Figura 7: Distribuição espacial das cicatrizes de acordo com o uso e cobertura da terra do alto curso da bacia do rio Grande, Nova Friburgo, RJ.

Estes dados não expressam a influência da cobertura da vegetação no desencadeamento dos movimentos de massa em 2011. A vegetação densa tende a estar situada em área menos acessível como encostas com alta declividade. Francisco, Carvalho e Salgado (2019) demonstraram que os valores da declividade da cobertura vegetal alternam de $19^{\circ}$ a $17^{\circ}$, respectivamente, variando da vegetação de maior porte (arbórea-arbustiva) a menor porte (campo antrópico), enquanto, as classes agrícola e urbana apresentam os menores valores de declividade média, respectivamente, de $14^{\circ}$ e $12^{\circ}$.

Varnes (1984) corrobora o papel dúbio exercido pela cobertura vegetal na estabilidade das encostas que, dependendo da profundidade do solo, declividade e tipo de vegetação, atua reduzindo a ação dos agentes climáticos ao reter a água da chuva na serrapilheira, eliminar a água pela evapotranspiração, imobilizar grande quantidade de água do runoff e erosão, além do sistema de raízes aumentar a resistência e a coesão dos solos. Por outro lado, afirma que a carga exercida pelas árvores sobre os solos de encostas íngremes e a ação das raízes na ampliação das fraturas e promoção da infiltração deterioram as condições de estabilidade da encosta. Segundo Bigarella (2007), os movimentos de massa em áreas de floresta estão relacionados, sobretudo, à presença de solos 
pouco desenvolvidos, encostas de alta declividade e eventos pluviométricos de alta intensidade e concentração espacial.

\section{Conclusões}

As quinze regras de associação entre os condicionantes e as cicatrizes, geradas pelo algoritmo Apriori com suporte entre 0,70 a 075 , revelaram que os padrões de ocorrência dos movimentos de massa de 2011, no alto curso do rio Grande, são constituídos por encostas com curvatura convergente e côncava, em relevo montanhoso, na faixa altimétrica de 1.000 a 1.200 m e cobertas por vegetação herbácea.

No entanto, deve ser destacada a curvatura das encostas, principalmente, a horizontal, como o condicionante mais relevante, pois foi incluída em treze regras como atributo consequente, possivelmente devido as corridas de massa terem sido um dos principais tipos de movimentos de massa ocorridos em 2011 na região serrana.

A análise da distribuição espacial das cicatrizes confirmou as regras geradas pela mineração. Nas classes dos condicionantes revelados pelo Apriori - curvatura convergente e côncava, relevo montanhoso, faixa altimétrica 1.000-1.200 m e vegetação herbácea, as cicatrizes prevaleceram frente as demais classes. No entanto, na altimetria e uso e cobertura da terra não houve prevalência expressiva em nenhuma classe, o que confirma a menor relevância destes condicionantes, como também apontada pela mineração de dados.

Desta forma, conclui-se que os eventos desencadeados pelas fortes chuvas, que atingiram a região serrana fluminense 2011, tiveram predominância nas encostas com convergência de fluxos e com alta declividade e, assim, provavelmente, a combinação destes condicionantes geomorfométricos promoveu os eventos de elevada magnitude na região.

Estes resultados fortalecem a necessidade de políticas públicas que restrinjam a ocupação de encostas com estas características na intenção de poupar perdas de vidas e econômicas. Neste sentido, deve-se apontar a importância das Áreas de Preservação Permanente (APP), que protegem as encostas inclinadas bem como as faixas marginais de cursos d'água, e que apresentam como função, entre outras, preservar a estabilidade geológica. No entanto, neste ponto, deve ser avaliado se os atuais parâmetros delimitadores das APP são suficientes para diminuírem a magnitude das catástrofes como a que ocorreu em 2011.

Por fim, deve ser apontado, que a utilização do algoritmo Apriori para a mineração possibilitou a descoberta de padrões em um banco de dados volumoso, de forma rápida e de fácil interpretação, tendo, assim, contribuído para o conhecimento sobre as características da fisiográficas associadas mais frequentemente às encostas atingidas por movimentos de massa em 2011.

Contribuições dos Autores: Todos os autores leram e concordaram com a versão publicada do manuscrito.

Financiamento: Esta pesquisa não recebeu nenhum financiamento externo.

Conflito de Interesse: Os autores declaram não haver conflito de interesse.

\section{Referências}

1. AGRAWAL, R.; SRIKANT, R. Fast algorithms for mining association rules. In: INTERNATIONAL CONFERENCE ON VERY LARGE DATA BASES 20., 1994, Santiago. Proceedings... São Francisco, EUA: Morgan Kaufmann Publishers Inc., 1994. p. 487-499. DOI: 10.1007/978-3-642-31319-6_51

2. AVELAR, A.; COELHO NETTO, A.L.; LACERDA, W.A.; BECKER, L.B.; MENDONÇA, M.B. Mechanisms of the recent catastrophic landslides in the mountainous range of Rio de Janeiro, Brazil. In: WORLD LANDSLIDE FORUM, 2, Roma, 2011. Proceedings... Roma: International Programme on Landslides (IPL), 2011. CD Rom. DOI: 10.1007/978-3-642-31337-0-34

3. AYALEW, L.; YAMAGISHI, H. Slope movements in the Blue Nile basin, as seen from landscape evolution perspective. Geomorphology, v. 57, n. 1-2, p. 5-116, 2004. DOI: 10.1016/S0169-555X(03)00085-0

4. AYALEW, L; YAMAGISHI, H; UGAWA, N. Landslide susceptibility mapping using GIS-based weighted linear combination, the case in Tsugawa area of Agano River, Niigata Prefecture, Japan. Landslides, v. 1, p. 73-81, 2004. DOI: 10.1007/s10346-003-0006-9

5. BANCO MUNDIAL. Avaliação de Perdas e Danos: Inundações e Deslizamentos na Região Serrana do Rio de Janeiro Janeiro de 2011. Brasília, DF, 2012.

6. BIGARELLA, J. J. Estrutura e Origens das Paisagens Tropicais. Florianópolis: UFSC, v.3, 2003, 561p. 
7. CANEDO, P.; EHRLICH, M.; LACERDA, W. A. Chuvas na região serrana do Rio de Janeiro: Sugestões para ações de engenharia e planejamento. Rio de Janeiro: COPPE/UFRJ, 2011.

8. CHAGAS, D. J.; CHAN C. S.; CORSI, A. C. Análise do Banco de Atendimentos da Defesa Civil do Estado de São Paulo. Anuário do Instituto de Geociências - UFRJ, v. 33, p. 35-43, 2010. ISSN 0101-9759.

9. COELHO NETTO, A. L.; SATO, A.M; AVELAR, A.S.; VIANNA, L.G.G.; ARAÚJO, I.S.; FERREIRA, D.L.C; LIMA, P.H.; SILVA, A.P.A; SILVA, R.P. January 2011: The extreme landslide disaster in Brazil. In: WORLD LANDSLIDE FORUM, 2, Roma, 2011. Proceedings... Roma: International Programme on Landslides (IPL), 2011. CD Rom. DOI

10. DAI, F.; LEE, C. Landslide characteristics and slope instability modeling using GIS, Lantau Island, Hong Kong. Geomorphology, v. 42, n. 3, p. 213-228, jan. 2002. DOI: 10.1016/S0169-555X(01)00087-3

11. DANTAS, M. E. Geomorfologia do Estado do Rio de Janeiro. In: CPRM. Serviço Geológico do Brasil. Estudo Geoambiental do Estado do Rio de Janeiro. Brasília, CPRM, 2001. p. 1-63. DOI: 10.13140/RG.2.2.32582.57923

12. DOURADO, F.; ARRAES, T. C.; SILVA, M.F O Megadesastre da Região Serrana do Rio de Janeiro - as Causas do Evento, os Mecanismos dos Movimentos de Massa e a Distribuição Espacial dos Investimentos de Reconstrução no Pós-Desastre. Anuário do Instituto de Geociências, vol. 35, n. 2, p.43-5, 2012. ISSN 0101-9759

13. DRM. Departamento de Recursos Minerais do Estado do Rio de Janeiro. Megadesastre da Serra, 2011. Disponível em: http://www.drm.rj.gov.br/index.php/downloads/category/13-regio-serrana.html?download=48\%3Amegadesastre-da-serrajan-2011-pdf. Acesso em 1 mar. 2021.

14. EMBRAPA. EMPRESA BRASILEIRA DE PESQUISA AGROPECUÁRIA. Serviço Nacional de Levantamento e Conservação de Solos (Rio de Janeiro, RJ). Súmula da 10º . Reunião Técnica de Levantamento de Solos. Rio de Janeiro, EMBRAPA-SNLCS, 1979.

15. ESRI. How Topo to Raster works. [S. 1.], 2020. Disponível em: https://pro.arcgis.com/en/pro-app/tool-reference/3danalyst/how-topo-to-raster-works.htm. Acesso em: 09 jul. 2020.

16. FERNANDES, N. F.; AMARAL, C. Movimentos de massa: uma abordagem geológico-geomorfológica. In: GUERRA, A. J. T.; CUNHA, S. B. (org.) Geomorfologia e Meio Ambiente. Rio de Janeiro: Bertrand, 2003, p. 123-194. ISBN: 8528605736

17. FERNANDES, N. F.; GUIMARÃES, R.F.; GOMES, R.A.T.; VIEIRA, B.C.; MONTGOMERY, D.R.; GREENBERG, H. Condicionantes Geomorfológicos dos Deslizamentos nas Encostas - Avaliação de Metodologias e Aplicação de Modelo de Previsão de Áreas Susceptíveis. Revista Brasileira de Geomorfologia, v. 2, n. 1, p. 51-71, 2001. ISBN $2236-5664$

18. FRANCISCO, C.N.; CARVALHO, R.C.; SALGADO, C.M. Condicionantes geomorfológicos e da cobertura da terra na ocorrência de movimentos de massa na região serrana do Rio de Janeiro. Caderno de Geografia, v. 29, p. $27,2019$. DOI: 10.5752/P.2318-2962.2019v29n56p27

19. FRANCISCO, C. N.; ALMEIDA, C. M. Classificação de cobertura da terra de Nova Friburgo-RJ utilizando duas abordagens: mineração de dados e rede heurística. Revista Brasileira de Cartografia, v. 64, n. 3, 2012. p. 645-660, 2012. ISSN: 1808-0936

20. FRANCISCO, C. N. Mapeamento das áreas de risco de deslizamentos e desmoronamentos do Parque Nacional da Tijuca (RJ) e entorno através de sistemas geográficos de informação. In: SEMANA ESTADUAL DE GEOPROCESSAMENTO, 1, 2016. Anais...Rio de Janeiro, p. 197-209, 1996.

21. GARCIA, M. L. T.; FRANCISCO, C. N. Métricas da paisagem no estudo da vulnerabilidade da Mata Atlântica na região serrana fluminense - Nova Friburgo, RJ. SIMPÓSIO BRASILEIRO DE SENSORIAMENTO REMOTO, 16, 2013, Anais...Foz do Iguaçu, PR p. 3268-3274, INPE, 2013. ISBN: 978-85-17-00066-9

22. GONÇALVES, U. S., FRANCISCO, C. N. Análise espacial das variáveis geomorfométricas e movimentos de massa na Região Serrana Fluminense. Revista Brasileira de Cartografia, Rio de Janeiro, RJ, v. 68, n. 9, Edição Especial Movimentos de Massa e Processos Erosivo. p. 1839-1851, out. 2016. ISSN: 1808-0936

23. HAN, J.; KAMBER, M.; PEI, J. Data Mining: Concepts and Techniques. 3.ed. Walthan: Elsevier, 2012.740 p. ISBN: 9788131205358

24. HIGHLAND, L. M.; BOBROWSKY, P. The Landslide Handbook: A Guide to Understanding Landslides. Virginia: U.S. Geological Survey. 2008. 129 p.

25. HUTCHINSON, M. F. A new method for gridding elevation and stream line data with automatic removal of spurious pits. Journal of Hydrology, v. 106, p. 211-232, abr. 1989. DOI: 10.1016/0022-1694(89)90073-5

26. IBGE. Base cartográfica contínua do estado do Rio de Janeiro na escala 1:25.000 - BC25_RJ - versão 2018. Disponível em: $<$ http://www.metadados.geo.ibge.gov.br/>.

27. LEE, S.; MIN, K. Statistical analysis of landslide susceptibility at Yongin, Korea Environmental. Geology, v. 40, n. 9, p. 1095-1113, ago. 2001. DOI: 10.1007/s002540100310 
28. PINHO, G. M., FRANCISCO, C. N., SALGADO, C. M. Análise espacial de movimentos de massa em Nova Friburgo, RJ: O caso do desastre natural de janeiro de 2011. Revista Tamoios, São Gonçalo, RJ, v. 9, n.1, p. 16-27, jan/jul. 2013. DOI: 10.12957/tamoios.2013.5355

29. REGMI, N. R.; GIARDINO, J. R..; VITEK, John. D. Characteristics of landslides in western Colorado, USA. Landslides, v.4, n. 11, p. 589-603, 2014. DOI: 10.1007/s10346-013-0412-6

30. SILVA, M. P. S. Mineração de Dados: Conceitos, aplicações e experimentos com WEKA. Disponível em: <http://www.lbd.dcc.ufmg.br/colecoes/erirjes/2004/004.pdf>. Acesso em: 4 dez. 2016. ISBN: 9788547200985

31. VARNES, D. J. Landslide hazard zonation: a review of principles and practice. Paris: UNESCO Press, 1984, 63p.

32. VALERIANO, M. M. Topodata: guia para utilização de dados geomorfológicos locais. São José dos Campos, INPE. 75 . 2008. Disponível em http://mtc-m18.sid.inpe.br/col/sid.inpe.br/mtc-m18@80/2008/07.11.19.24/doc/publicacao.pdf. Acesso em: 4 dez. 2016.

Esta obra está licenciada com uma Licença Creative Commons Atribuição 4.0 Internacional (http://creativecommons.org/licenses/by/4.0/) - CC BY. Esta licença permite que outros distribuam, remixem, adaptem e criem a partir do seu trabalho, mesmo para fins comerciais, desde que lhe atribuam o devido crédito pela criação original. 